Journal of Universal Computer Science, vol. 18, no. 1 (2012), 106-122

submitted: 15/7/11, accepted: 9/12/11, appeared: 1/1/12 @ J.UCS

\title{
Clustering Projects for eLearning Interoperability
}

\author{
Marc Alier, Enric Mayol, Maria Jose Casañ, Jordi Piguillem \\ (Universitat Politècnica de Catalunya - Barcelona Tech, Barcelona, Spain \\ ludo@essi.upc.edu, mayol@essi.upc.edu,mjcasany@essi.upc.edu, jpiguillem@essi.upc.edu)
}

Jeffrey W. Merriman

(Massachusetts Institute of Technology, Cambridge, Massachusetts, USA

merriman@mit.edu)

\author{
Miguel Ángel Conde, Francisco J. García-Peñalvo \\ (University of Salamanca, Salamanca, Spain \\ mconde@usal.es,fgarcia@usal.es) \\ Wouter Tebbens \\ (Free Knowledge Institute, Amsterdam, The Netherlands \\ wouter@freeknowledge.eu)
}

Charles Severance

(University of Michigan, Ann Arbor, USA

csev@umich.edu)

\begin{abstract}
Since the beginning of the discipline, eLearning has been about innovation. New software, systems, contents and tools are being created and experimented with and in constant evolution. But when systems, contents and tools become successful and part of the regular infrastructure of educational institutions, interoperability becomes an issue. Systems that are consolidated and regularly used need to be able to interoperate with new ones. And the new tendencies need to fit within the current infrastructure. This paper states how several research and development projects with heterogeneous funding sources and locations worldwide, gathered together to find a solution to this common problem, providing open specifications and standards, plus Free/Libre, Open Source reference implementations.
\end{abstract}

Keywords: E-Learning, Interoperability, Open Standards, Open Source, Free Software, LMS, Sakai, Moodle, IMS LTI, OKI, SOA, Software as a Service

Categories: D.0, D.2.12, K.3.1, L.2.0, L.2.3, L.3.0, L.3.5, L.3.6

\section{Introduction}

When universities and learning institutions face the decision of which Learning Management System (LMS) are going to use to implement their virtual campuses, they are choosing in fact the toolbox of learning applications they will use (those included or compatible with the LMS of choice) but they are choosing also the learning applications they will not be able to use further on. Today, LMS offers a standardized set of tools. Most of them provide, with small variations and implementation details, the same kinds of packaged content compatibility, standards 
for quizzes and learning tools. They are integral, if not mission critical, elements of a university's teaching and learning infrastructure [Obexer and Bakharia 05]. LMS have achieved stability and maturity: we are in the Golden Age of LMS. LMS adopt each other's features and are slowly beginning to look like clones one of another. Given the wide range of didactic opportunities that the Web 2.0, social networks, cloud based services and mobile applications have to offer nowadays, the set of features of any LMS is surely not enough [Brown and Adler 08], [Wesh 09], [O’Reilly 07].

In some way, a LMS is like a Swiss army multi-purpose knife. It offers a big collection of tools nicely integrated. But these tools may not be the best available tools or the most suitable for the job. For instance, you can get a better screwdriver on a hardware store, but you will not be able to bundle it with the other tools on the Swiss army knife. If the Swiss army knifes would come with a standard socket where you could insert new tools that would make this multi-purpose knives even more useful; then, it would be also of interest for third party hardware makers to comply with the standard socket specification because of the new business opportunities that would open.

Without pushing the metaphor any further, would it not be nice to have an easy way to make online learning tools interoperable so they can work within many LMSs seamlessly? This also applies for back-end academic information systems that need to be merged with an LMS and other related applications.

But the reality is that creators of new eLearning tools face up the following dilemma: either they create a version of their tool to be compatible with every LMS any possible customer might have, or they will be limited to a part of the market. Therefore, they need to choose what part of the market to deal with. If all vendors started developing for just a few LMS we might face a future with very few LMSs and there would be a huge cost to introduce a new one in the market, due to the lack of compatibility with tools and contents. Certainly that is not a way to encourage innovation.

Current learning innovation practices do not fit inside the bounds of the current crop of LMS (Moodle, Sakai, Angel, Blackboard etc.). Innovation may come from several directions: (1) The new generations of mobile devices have escaped from the fences that telecommunications operators have been erecting for so long, and becoming platforms opened to software developers ready to create great mobile learning applications [Vavoula and Sharples 02], [Bull and Reid 04]. (2) The next generations of game consoles and all sorts of gadgets that surround us in our digital life, ready to be part of our learning processes [Squire 05]. (3) The so-called Web 2.0 which is not really a new technology, but it is the way that people have decided to relate to their peers through technological means: an enhanced way to relate to others, produce, share and consume information. Relations among students, production and consumption of information are the basic tools of education [Downes 05], (4) Virtual worlds [Freitas 06] and simulation technology provide advanced tools to improve elearning environments, and, (5) learning content design and production may contribute definitely to an e-learning evolution.

The LMS is a common ground for teachers and learners. Therefore, the LMS itself may also be the means to spread learning innovation, because teachers and learners want (or ought) to use them. We think that the right approach to spread 
innovation and transform learning will actually come from within the LMS itself [Alier et al 10a].

To avoid extinction or becoming a barrier for the spreading and adoption of learning innovations and contents, LMSs need to evolve and adapt to what is coming next [Sclater 08]. But, what kind of evolution are we talking about? Is it about features? No. It is about flexibility and interoperability.

This paper describes how several research and development projects, with heterogeneous funding sources and locations worldwide, gathered together to find a solution to this common problem, e-learning interoperability, by providing open specifications and standards, plus reference implementations in Free Software (http://www.gnu.org/philosophy/free-sw.html), as well known as Libre Software or Open Source Software (http://www.opensource.org/docs/osd) - we'll use the abbreviation FLOSS in this article. Section two presents the main standards of elearning interoperability. Section three describes a set of e-learning projects in which authors have participated and where these standards have been used. Section four describes lessons learned from these projects and introduces a new project that benefits from the previous experiences. Finally, section five summarises the main conclusions of the paper.

\section{2 e-learning interoperability standards}

Interoperability in the e-learning field is addressed mainly by specifications and standards. In this section, we describe two of the main existing initiatives to accomplish interoperability between LMSs and external applications: the OKI [OKI 02] [Franc 08] and the IMS-LTI [IMS-GLC 09a] [IMS-GLC 09b] initiatives.

The definition of a standard requires a fair document of specification and some institution willing to put its stamp on it and to promote it as a standard. But, in fact, to have a useful standard and really accepted by the market, it takes a lot of more. In the field of e-learning we have plenty of examples of specifications with little or zero market adoption. To have a real standard, we need FLOSS reference implementations, key market adopters and, last but not least a community of practitioners that debate about the standard, its implementation guidelines and its evolution [Olivier and Liber 01].

\subsection{The Open Knowledge Initiative}

The Open Knowledge Initiative (O.K.I.) was launched in 2001 through a generous contribution from the Andrew W. Mellon Foundation and led by the Massachusetts Institute of Technology (MIT). The goal of O.K.I. and the 8 other institutions of higher education that participated in the initial project was to develop architectural models to support service-level interoperability of educational software. The goals the project outlined ten years ago are still central to today's educational technology landscape:

- To enhance the ability of learning technologies (appropriate for a range of teaching and learning requirements) to be integrated together and into educational infrastructures. 
- $\quad$ To easily share educational applications and services among institutions as a catalyst for cooperative and commercial development.

- To have lower long-term cost of educational software ownership, as well as high stability and reliability.

To this end, O.K.I. developed and published the Open Service Interface Definitions (OSIDs) whose design was and continues to be informed by a broad architectural view. The OSIDs define important components of a Service Oriented Architectural (SOA) as they describe general software contracts between service consumers and service providers in the form of interfaces. This architectural model enables software applications to be constructed independently of any particular service environment, and it facilitates integration. For technology consumers, the OSIDs are designed to allow end-user choose tools by enabling plug-in interoperability [OKI 02].

Without common interface abstractions, accessible through Application Program Interfaces (APIs), application developers are forced to "hard-code" underlying technical details and business logic of the enterprise into applications themselves, reducing drastically application portability. By defining common, implementation independent interfaces, which can cover up one or more implementations of critical services, the OSIDs provide developers with an important element of flexibility and control.

The OSIDs carefully parse the application/service and provide developers with common mechanisms for utilizing well-defined services. APIs for the services defined by OSIDs provide the right level of abstraction and the hiding of technical and business complexities of services to the developers. Java API bindings of the OSIDs were released by the O.K.I. project under a FLOSS license in 2003, and PHP bindings were released in 2004. The raw OSID interfaces are specified independently of any programming language using XML, and they can be bound to the interface abstraction technology of any programming environment.

The OSID Version3 draft is currently being refined taking into account feedback from several educational technology projects. This open development methodology of the specifications combined with the irrevocable rights to use and copy them from the O.K.I. SID API Definition License and the existence of reference implementations in FLOSS software assure this to be an open standard specification (See open standards definition: http://freeknowledge.eu/definitions/openstandards). This draft specification is available at http://www.assembla.com/wiki/show/osid-dev.

\subsection{Introduction to IMS GLC interoperability standards}

IMS Global Learning Consortium (GLC) is a non-profit organization that works in the development, adoption, and impact of open vendor-neutral information technology infrastructure for learning. IMS GLC published more than 20 standards about Content Packaging, Common Cartridge, Enterprise Services, Question \& Test, Competencies, ACCess for All, ePortfolio, Tools Interoperability o Learning Design, all widely used in the educational sector. Their specification and documentation are accessible to anybody and may be downloaded from the IMS GLC web site. They may also be used to create implementations without paying any license or fee. 
Since 1997, every year IMS GLC organizes conferences like the Learning Impact Conference and other workshops over the world, in order to broadcast their work and to gather feedback from educational and technical community.

IMS GLC has published several specifications related to the integration of external applications into LMSs. The Tool Interoperability (TI) specification was presented in 2005. IMS TI is a standard to integrate external applications into the LMS using Service Oriented Architectures (SOA). A new version of this standard was presented as Learning Tools Interoperability (LTI) in 2008. Meanwhile, Dr. Charles Severance proposed a simplified version of LTI named SimpleLTI that became a temporal solution to integrate applications before publication of the official version of LTI.

\subsubsection{IMS Tool Interoperability}

The IMS Tools Interoperability (TI) is a standard that provides a generic way to integrate external applications into the LMS. The goal of TI is that after an external application is integrated into the LMS, this application looks like a LMS native tool to the user. IMS TI is based on a client/server architecture where client is the LMS and the server is the external application. Therefore, information and functionality of the external application is provided to the LMS by means of web-services.

The basic idea of IMS TI is that the LMS has a proxy tool that provides an endpoint for an externally hosted tool making it look like it is running within the LMS. The proxy tool also provides to the external application information about the individual, course, tool placement, and role within the LMS course. In a sense the proxy tool allows a single-sign-on behind the scenes using web-services and allows an external tool to support many different LMS's with a single instance of the tool.

IMS TI specification can be combined with other IMS GLC standards such as:

- IMS General Web-Services: a standard that defines a layered architecture to implement web-services in e-learning.

- Simple Object Access Protocol: a XML-based transport protocol used by web-services.

- IMS Question \& Test Interoperability: a standard that defines how external tools must return results to the LMS.

\subsubsection{IMS Learning Tools Interoperability}

IMS Learning Tools Interoperability (LTI) is the evolution of IMS TI. After some successful implementations of TI, IMS GLC has been working in a new version of this standard, which will extend and improve the features of the previous version. The main differences between LTI and TI are: 1) LTI has a mechanism to provide logging information about the learning activity generated in the external application into the LMS itself and 2) LTI provides techniques to integrate external application interfaces into the LMS.

The IMS LTI architecture focuses on the launch phase of external tool from the LMS. The launch accomplishes several things in a single web-service call:

- Establish the identity of the user.

- Provide directory information (first name, last name, and e-mail address) for the user. 
- Indicate the role of the current user as administrator, instructor or student.

- Provide information about the current course where the proxy tool is being executed, such as course identifier and title.

- Other hints as display size.

\section{The case-study for e-learning interoperability}

\subsection{The beginning}

On 2005, Prof. Dr. Llorenç Valverde, vice-president of the Universitat Oberta de Catalunya (UOC), initiated a project to renew the legacy virtual campus of this catalan online university. It was a strategic decision since, being the UOC an online university, the virtual campus was their main infrastructure. He had considered three options: to keep the legacy virtual campus or to choose between the two main FLOSS LMSs in the marked: Moodle (http://moodle.org) and Sakai (http://sakaiproject.org). Each option was appealing but at the same time had its drawbacks.

The selection of one of the previous options, would limit the learning process to the available tools inside the chosen LMS. Often, the selection of one single LMS/virtual campus allows the institution to keep control over the administrative processes; and to provide a unique, secure, scalable, reliable ... front-end to students.

Dr. Valverde did not compromise and chose what he whished for. He chose all three options altogether: To keep the legacy campus and to adopt Moodle and Sakai LMSs.

Therefore, the strategic decision became a technical decision: "How can we make different Learning Management Systems (LMS) / Course Management Systems (CMS), different academic administration systems and a collection of Learning Tools work together in a way we can rely upon and keep sanity?". Turned out that UOC was not the only university facing this problem.

When a research and development project starts, there is the temptation to define the whole architecture starting form a clean stale. Coming up with an elegant design, just like students learn in engineering schools. But the ones pushing for a new creation also want their project to spread and gain adopters; and they don't want to find solutions for old problems that other may had solved before, they want to focus in what makes the new project special. So, at the beginning of new projects, there are many people who hunt for standard frameworks and interoperability architectures, in order to maximize the chance of success of the project, even if it implies not to start from a clean slate.

The new approach adopted by UOC was based on reusability rather than software development. The general idea was to create a platform to enable existing learning platforms - like Moodle, Sakai, the old UOC Virtual Campus and others - to interact with external tools and services [Garreta and Santanach 10].

\subsection{The Campus Project}

The Campus Project came under the Digital University program fostered by the Catalan government STSI department on 2005 with a tree million Euros award. The Open University of Catalonia (UOC) was the manager and leader of the project, 
which was carried out using the knowledge and experience of each associated university, and their contribution with specific tools and resources. The consortium of the Campus Project had over 15 partners who shared development, observation and monitoring tasks responsibilities. The project officially began on April 2006 and delivered its results to the community in 2008.

The aim of the Campus Project was to develop a technological infrastructure to provide online training based on FLOSS tools. The project requirements where:

- FLOSS and open standards,

- User-centred design

- Interoperability between tools and with other systems

- Scalability of the solution,

- High concurrence of users and processes

- OKI OSIDs5 as a mechanism of interoperability, which can be executed and integrated into Moodle [Conde et al. 09] and Sakai [Farmer and Dolphin 05] platforms and with a service-based architecture solution.

The Campus Project and its follow-on initiatives have provided critical input and guidance to the development of the architectural models that define the OSID V3 specification. Since 2007, UOC, MIT, Tufts University and a handful of other organizations have provided financial resources and technical feedback that has been critical and essential to the continuous advancement of the OSID specifications.

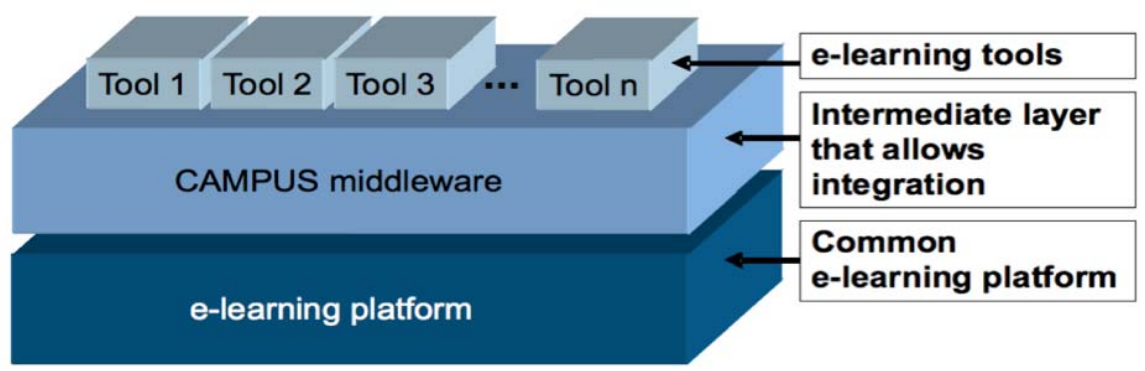

Figure 1: Campus project architecture [Santanach et al. 07a]

On the functional point of view, the Campus Project is a solution designed for virtual learning that contemplates the common functions of an LMS [Mackenzie et al. 06], but which also offers tools that can be executed and integrated into the Moodle and Sakai platforms (through OKI) bringing added value to the functionality offered by such platforms. A global view of this structure is shown in Figure 1. In particular, tools providing functionalities that are not present in Moodle or Sakai are candidates to be integrated to the Campus project platform. However, tools providing functionalities similar to these LMSs but with different pedagogical approaches are also welcome, and, in a similar way, such tools contributing with any additional value to the platform. 


\subsubsection{OKI Campus Collaboration.}

While the Campus project was a project that aimed to bind together learning tools, back office infrastructure and LMSs, the Open Knowledge Initiative (OKI) was working on the definition of an interoperability standard and to have reference implementations and feedback from application cases. On 2006, OKI and the Campus Project initiated some contacts and a close collaboration to be a reference of the OSIDs adoption.

The Campus project adopted the OKI OSIDs in its base architecture to implement the Communication Bus between learning applications and tools $(\mathrm{M} 1, \ldots, \mathrm{Mn})$ and both LMSs. The OSIDs provide an abstract layer for interfacing LMS and tools (see Figure 2).

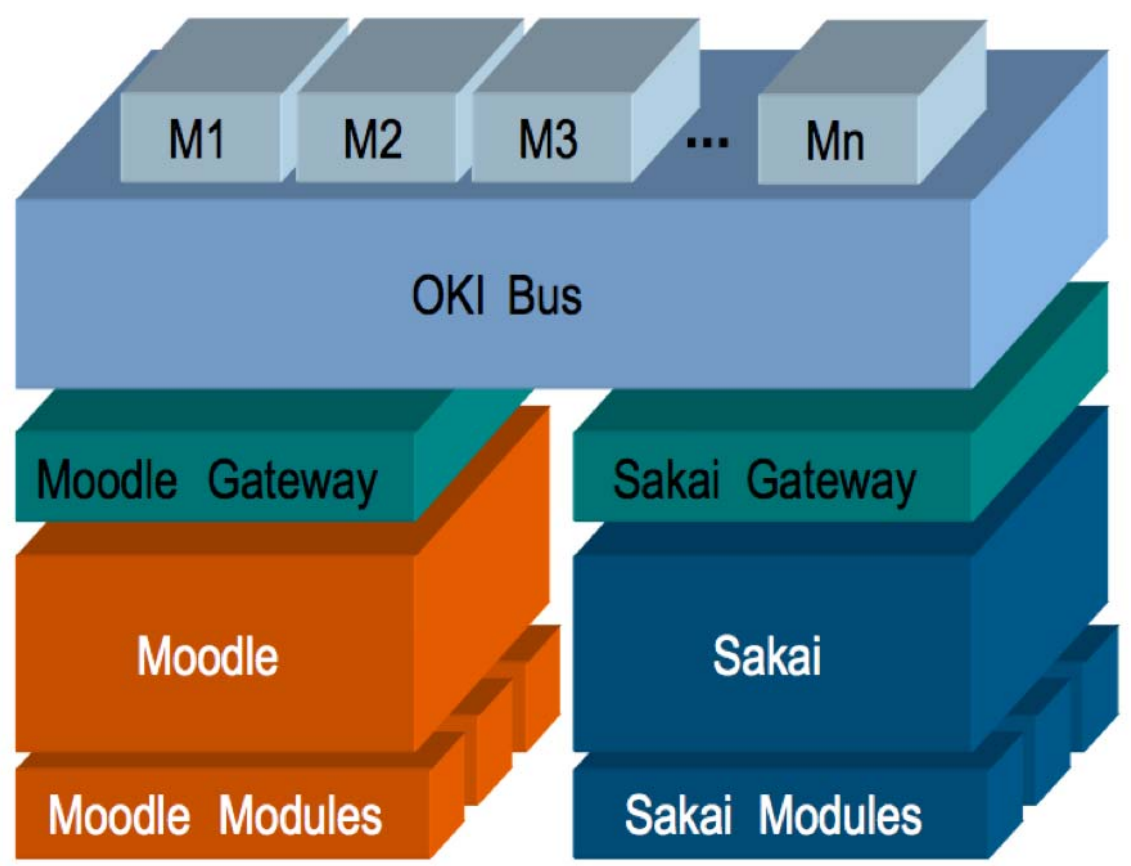

Figure 2: The Campus project architecture [Santanach et al. 07a]

OKI provided an interoperability specification to solve the main problem of the campus project: an abstract way to interface tools and LMSs. But Campus had in mind to work with Sakai and Moodle as base FLOSS LMSs. These LMSs are implemented in different platforms: Sakai in Java and Moodle in PHP.

On 2007, the first "PHP OKI Summit" [First PHP-OKI 07] was held at the Middlebury College between members of the Middlebury College, OKI, MIT, Apple, MoodleRooms, UCLA, UOC and UPC. During the summit there was a debate on how to solve semantic issues in OSID's v2. Two main results of this meeting were the agree that the OSID's v3 will be released, and that FLOSS PHP reference 
implementations of the OSID's were developed for the Moodle, Segue and Concerto platforms (http://www.phpoki.org/).

On the OpeniWorld Conference edition of 2008, organized by the Open Knowledge Initiative (http://www.openiworld.org/Europe2008.html), the Campus Project was distinguished with the Best Project Award..

The Campus Project has released all the planned tools and OKI connectors for Moodle and Sakai, under a GPL license on the project site (http://www.campusproject.org).

The Campus Project has been its continuation in the Suma Project (http://www.ines.org.es/suma/en) explained in Section 3.3, which was funded in the AVANZA Program of the Spanish ministry of industry, with the participation of UOC and UPC (Universitat Politècnica de Catalunya - Barcelona Tech), both former Campus Project partners, and several companies and other universities in Spain.

\subsubsection{Campus and the IMS Global Learning Consortium}

OKI's OSIDs solved interoperability issues and provided developers with a standard framework for tool development. But people from Campus Project faced a new challenge: installing those tools and interact with them from different LMSs as if they were native tools from these platforms.

Tool Interoperability (TI) [IMS-GLC 09a] is an IMS GLC's specification that proposes a reusable mechanism for integrating third-party tools with the core LMS platform. Campus Project members developed three activity modules which implemented TI, one for each LMS. By combining OSIDs and TI, the Campus platform achieved full interoperability in eLearning platforms. TI was used to integrate external tools inside the LMS and send information from LMS to tools whereas OSIDs were used to retrieve and insert information into the learning platform from the third-party tools.

On 2007 Dr. Charles Severance, former lead developer of the Sakai project and professor at the University of Michigan joined IMS with the task of managing the development of the Learning Tools for Interoperability [IMS-GLC 09b] project, a more complete solution than IMS TI because it would incorporate the functionality of LMS-Tool communication (solved by the OSID's in the Campus project) into the standard. Dr. Severance decided to create the LTI standard bottom up, developing reference implementations, producing working and useful code and engaging the companies and FLOSS communities from the very beginning. As opposed to creating a huge document and waiting for the market to adopt the spec after were published.

The UPC researcher Dr. Alier was appointed in 2009 to represent Moodle in the IMS Global Learning Consortium in the preparation process of the LTI Standard. In this participation, the Phd Student of UPC Jordi Piguillem received a Google Summer of Code award [Severance et al. 10] to develop a first approach to LTI: SimpleLTI. When the BasicLTI, the first official specification of LTI to be published by IMS, was defined [IMS-GLC 09b], the UPC team with the guidance of Dr. Severance developed the Moodle consumers for IMS BasicLTI for Moodle 1.9 and Moodle 2.0. At present, the Moodle community is revising the code to include it on Moodle 2.1 as part of the official distribution [Alier et al. 10b]. 
On 2010 Google gave the UPC team an award to develop a Google Docs connector for BasicLTI that allow LMS, like Moodle or Sakai, to use Google Docs as course activities (http://code.google.com/p/gdocs-task/).

\subsubsection{Campus project implemented outside the consortium}

The first project to implement the campus outside of the Campus Project consortium is the Free Technology Academy (FTA). In 2008 the Free Knowledge Institute (FKI) got awarded a Lifelong Learning Project from the EC in the area of Virtual Campuses. With a consortium lead by the FKI together with UOC, Open University Netherlands and the University of Agder, the FTA Consortium takes off to set up an online campus completely based on Free Software and Open Standards, with courses on precisely these topics and with all course materials published as Open Educational Resources. The development team is formed by the UOC (led by Francesc Santanach) and the FKI, to assure knowledge transfer about the campus project towards the FTA consortium [Megias et al 09].

The FTA Campus uses the OKI Bus as an integration layer to integrate Moodle, WordPress, MediaWiki and OpenFire in the first phase. In the second phase two new tools are included: 1) the Elgg social networking software to form the FTA Community Portal and 2) a peer annotation tool called the Annotation Tool.

The first two years to set up the campus and its initial programme have been cofunded (300.000 Euros) by the EC's LLP and in part by the consortium. Learners were asked to pay a modest tuition fee per course module. The pilot programme in 2010 had three times more enrolled learners than expected (161 enrolments) and more than 100.000 downloads of openly published and freely licensed course books. This encouraged the consortium to continue running (non-subsidised) courses after the ECfunded period. Overall to date (16 November 2011) out of 1687 campus users, there are 243 community portal members, 95 unique enrolled learners, while 2722 people are following the FTA through its announce mailing list.

One of the aspects of interest is the FTA's open development model for open educational resources. Through the use of the Annotation Tool, MediaWiki, it is an open educational methodology in the online courses, partners, peers and learners are encouraged to contribute to the open development cycle [Tebbens et al. 10].

\subsection{The Suma project}

The Suma project (http://www.ines.org.es/suma/en/) is the continuation of the Campus project, but this time the main goal of the project is the development of interoperability solutions for e-learning companies.

As a result of the experience of the project partners that were part of the INES (http://www.ines.org.es/) e-learning group, a lack of standardisation in the e-learning solutions available on the market was detected. This situation involves a great deal of individual effort of the companies that implement e-learning environments, because they have to develop each time the solutions that customers expect. Each of these projects involves significant technological effort to develop and to adapt to the customer's needs as well as to integrate the e-learning solution as easily as possible into a business environment [Santanach et al. 2007b]. 
Consequently, in most cases, the effective incorporation of e-learning solutions into a company involves not only a great deal of effort but also high costs, which means that it is not within every company's reach. Due to this, the major e-learning experiences are found mainly in large companies and in many cases are beyond the reach of medium and small companies. In addition, research carried out in the university environment (in the field of standards as well as processes and education methodologies in e-learning) is mainly done in the theoretical sphere (definitions, models, etc.), while little has been put into practice (beyond reduced pilot trials).

The consortium of companies, technology centres and universities participating in the Suma project is adapting the solution developed for the Campus project to the specific needs of the business environment. The main goal of this approach is to promote the transfer of technology between university and business companies and take advantage of the lessons learned in the Campus project.

From the technological point of view, the Suma project uses the same OKI architecture designed for the Campus project. On top of the Campus Middleware a series of e-learning tools for e-learning companies will be added. These tools or applications will be basically of three types:

- Integration modules with e-learning company's private systems.

- Multimodal access modules to provide access to the e-learning platform through Interactive Digital Television (IDTV) and mobile devices.

- Intelligent/adaptative learning environments in order to transfer mature research into the private sector.

The final result is a complete platform with innovative e-learning services that facilitate connectivity to pre-existing platforms in both the business and academic field. In the Suma web page (http://www.ines.org.es/suma/es/difusion.php) there are a group of videos showing demos of the platform and some presentations designed to communicate the project results.

[Barberá et al. 08] summarises the main results of three pilots of the e-portfolio component of the system. The Suma e-learning system is based on the definition of a competence profile of students and the organization, based on a set of competences and evidences. Considering individual needs of the user and the training plan to follow according to their professional objectives, a set of competences and evidences are identified. Three pilots are developed to validate the competence/evidence pedagogical model. First pilot was implemented in the internal training courses of the Digital Communications Department of the IBIT Foundation (http://www.ibit.com) to demonstrate the competence that a worker may submit a completed task without looking manuals and, at the same time, to determine how essential are these manuals. The second pilot is implemented on the CBIDJ (Balearic Centre for Youth Information and Documentation) in Digital Citizenship Course and Basic Courses in Youth Information Work to validate the e-portfolio as a on-line tool for online education. And in the last pilot, two virtual classrooms on Education Psychology courses of the UOC (Catalan Open University) are used to test the e-portfolio tool and to identify the student experience with competences and evidences, the teachers' role in the student monitoring process, and how close relationships between students and teachers are. 
The project was presented as a three-year plan (2007-2009) and has secured a subsidy for 2007 from the Ministry of Industry, Tourism and Trade of the PROFITICT Industrial Policy of the Plan Avanza.

\subsection{Contributions of the Campus project}

The collaboration between the Campus project and the OKI and IMS Global Learning Consortium (IMS) (http://www.imsglobal.org/lti/) has provided some unexpected but valuable outcomes for FLOSS communities.

UPC has some researchers actively collaborating within the Moodle community (http://sushitos.essi.upc.edu), contributing code to the official release and contribution modules in the trunk. The work of the OSID's implementation for Moodle funded the basis for a proposal of web-services architecture for Moodle. This architecture was presented to the Moodle lead developer, Martin Dougiamas, who agreed to incorporate web-services interoperability in the next release of Moodle: Moodle 2.0 officially released on 2010 [Alier et al. 10b].

The next release of Moodle 2.0 is likely to include the IMS BasicLTI consumer implemented by Dr. Alier's UPC Team.

Regarding the results of the Campus project, the first release of this SOA and open-standards-approach learning platform was in 2008 and supported 4,000 concurrent users. Keeping with the university's strategy of evolution, Campus 5.0 (the current version of the e-learning platform) is now a solid integration platform supporting the incremental addition of new e-learning services, rather than needing major version upgrades.

Campus 5.0 now has more than 20 tools available for teaching and learning. There are approximately 4,000 virtual "classrooms," with an average of six tools per classroom. Tools that have been integrated include WordPress, MediaWiki, Moodle classroom, Moodle activities into the UOC's classroom, Google Apps, Google widgets, Wikispaces, StatusNet, Kaltura, Dimdim, Adobe Connect and Openfire. Time to implement a new Web tool varies from a few days to a month at maximum. That time includes all phases, such as API investigation, graphical adaptation, implementation and testing.

[Lowendahl 11] identifies the key benefit to faculty using the Web 2.0 tools directly by themselves, as a way to provide a more relevant context for UOC campus users. This means an ability to build personalized information based on context, such as course or program, teacher, or classmates. After the first year of availability, more than 50,000 users have tried Campus 5.0: 40,935 students, 406 tutors, 2,067 faculty, 989 staff and 2,015 alumni. Campus 5.0 supports 6,000 concurrent users and has an average of 2,500 concurrent users.

According to [Lowendahl 11] the main contribution of the campus project lies in the brand of innovation that UOC has been able to build in its short existence. A realization that campus life needs to be redesigned (constantly) and technology needs to be ready for that has resulted in flexibility in pedagogy as well as technology. This flexibility built on open tools is the basis for even more collaborative projects that provide a constant influx of new ideas and, thus, create a positive spiral for UOC. However, technology is only a hard-earned enabler. The real success factor is an open collaborative mind-set in the institution as a whole - from the leadership team, via faculty and students, to the IT organization. 


\section{Learning Apps, the next generation}

The Campus and SUMA projects have a continuation in the new Learning Apps project. Learning Apps has been funded with 2.8 million Euros by the Spanish ministry of Science and Innovation within the INNPACTO program. Learning Apps project aims to be an on-line internet store, like the Apple Apps Store, but specialized on educational applications. Learning Apps is planned to take 2 years: from 2010 to 2012. Consortium of the project is composed of UOC as project leader, and the other partners are the UPC, Universidad Francisco Vitoria (UFV) and the companies Tecsidel, OpenTrends and ePractica.

Today, there exists a wide range of specific tools to support learning and teaching activities in the network. Some of them are specifically designed to learning purposes, but there are also more general tools that are becoming used for learning and teaching purposes. Educational institutions use mostly learning management systems (LMS) such as Moodle, Sakai and others. However, popularity and adoption of social networks (e.g. Facebook) into learning and education communities provoke an increasingly inclusion of e-learning initiatives and tools. At the same time, the number of Web 2.0 tools used for learning and teaching are also growing: wikis, blogs, Google Apps and video conferencing tools are more and more used by teacher, students and educational institutions.

Although these resources are already available in the cloud, the problem is that they are very disperse, making it very challenging to find, choose and use the right tool.

The Learning Apps project aims to reduce this dispersion by creating a space where teachers and educational institutions can easily find these tools, and as well as to build and personalise - with a single click - their own e-learning environment in the cloud. Hence, it will be possible to choose the most appropriate platform for teaching and learning - Moodle, Sakai, Facebook and so on - and the specific tools for each subject - blogs, wikis, chats, forums, video / audio conference and others -. The environment will also allow the addition of new tools, assessment of existing ones and attachment of information such as manuals, case studies, strategies and the contexts of use.

From the technical point of view, the first step to include learning apps into the Learning app Store platform is the registration of Learning Apps to the learning platform. Learning Apps applications are provided as Software as a Service (SaaS) or hosted in the learning platform. Learning Apps platform provides a series of web services to register learning apps applications in the learning platform. This registration process is implemented based on OKI's OSIDs.

The second step to use a learning app from the learning platform is the subscription process. The users who want to use specific learning tools must subscribe to the selected learning tools in order to use them. After that, the user may use the learning app as a service or integrate it in its own LMS installation, social network, intranet or server. Communication between the LMS/social network/intranet or server and the integrated learning app is implemented using the IMS BasicLTI specification.

To integrate a learning tool into the LMS using the IMS BasicLTI specification, a tool consumer and a tool producer must exist. The LMS (or other web systems) act as a consumer. In the LMS, the Tool Proxy Runtime is the engine that implements the BasicLTI protocol, which is necessary to integrate external learning tools into the 
LMS. The Learning Tool acts as a producer. The Learning tool must have a profile that is used to describe how the tool must be integrated. It also describes the webservices the learning tool is offering. The basic web-service to invocate the tool from the LMS is the launch service. This process is shown in Figure 3.

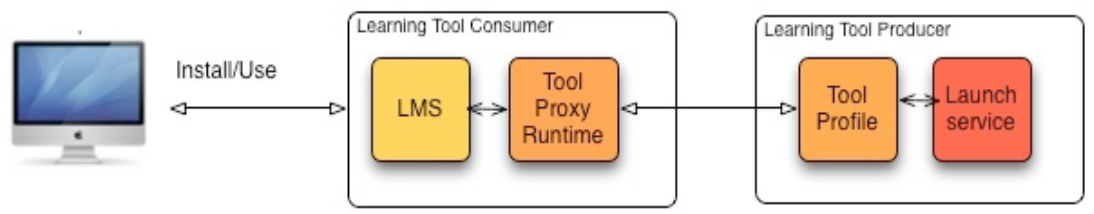

Figure 3: Learning Tool inside the LMS: Installation process

From an educational point of view, the Learning Apps project aims to provide a set of tools to facilitate and improve the learning process of students and, at the same time, the teaching activities of educators. The platform will be user-centered. The student has a set of available tools to select and he only has to 'click' which one to use, taking only into account his preferences, experience, purpose and desires. In a similar way, teachers may choose between several alternatives, the applications more adequate to the characteristics and the purpose of the learning activity they are designing.

In fact, the Learning Apps Platform will become the market place where learning tools providers will offer their applications to the community, and where students, teachers and educational institutions may find and acquire their learning tools.

Learning Apps will be a further step toward the technological model based on flexibility and interoperability between tools and e-learning platforms. This model has been promoted over the past 4 years by the Office of Learning Technology at the UOC and evolved thanks to projects like the FLOSS Campus, SUMA and Campus 5.0 .

\section{Conclusions and outcome}

The Campus and Suma projects have set up the basic technological infrastructure based on FLOSS tools to provide online training. They also allow the integration of external learning tools into the main learning platform. The main benefit for students is that the focus of the learning process is now the student (learner or student-centred). From the institution point of view, the main benefit of these projects is that as the learning process changes, technology needs to be ready for that. The designed architecture has resulted in flexibility in technology as well as in pedagogy.

The Learning Apps project goes a step further allowing the creation of a learning tool app store. It also allows the use of learning tools as a service so that final users do not need to know where the learning tool is hosted. This environment allows the use of any kind of web 2.0 tool for learning and its integration within the LMSs. Thus, we think that our project is a new step to allow LMSs continue being a source of innovation in learning. 
One of the main outcomes of the Learning Apps project is the adoption of IMS BasicLTI, by the major LMS vendors and App producers. Another outcome of the Learning Apps project is that an OKI OSID's reference implementation has been created for Moodle and Sakai.

\section{Acknowledgements}

This work has been funded by the "Spanish Ministry of Science and Innovation" (http://micinn.es) in project LearningApps in the program INNPACTO 2010, the project MiPLE code TIN2010-21695-C02-02.8 and Google Research Award.

\section{References}

[Alier et al. 10a] Alier, M., Casany, M.J., Conde, M.A., García-Peñalvo, F. J.: "Interoperability for LMS: the missing piece to become the common place for e-learning innovation"; International Journal of Knowledge and Learning (2010), 130-141.

[Alier et al. 10b] Alier, M., Casany, M.J., Piguillem, J.: "Moodle 2.0: Shifting from a Learning Toolkit to an Open Learning Platform"; In Technology Enhanced Learning. Quality of Teaching and Educational Reform. Springer Berlin Heidelberg, (2010) ISBN: 978-3-64213166-0, pp1-10.

[Barberá et al. 08] Barberá, E.; Almirall, M.; Mora, J., Monzó, A.; Llodrà. B.: "E-Portfolio: Learning by Competences. A Practical Application"; Proceedings of the iLearing Forum 2008 (iF'2008), (2008), Paris. pp.46-48. On-line access:

http://www.eife-l.org/publications/proceedings/ilf08.

[Brown and Adler 08] Brown, J.S., Adler, R.P.: "Minds on fire: Open education, the long tail, and learning 2.0"; Educause review (2008), 43, 16.

[Bull and Reid 04] Bull, S., Reid, E.: "Individualised Revision Material for Use on a Handheld Computer"; In J. Attewell \& C. Savill-Smith (eds.) Learning with Mobile Devices Learning and Skills Development Agency (2004), 35-42.

[Conde et al. 09] Conde, M.A., García-Peñalvo, F.J., Casany, M.J., Alier, M.: “Adapting LMS architecture to the SOA: an Architectural Approach"; In 2009 Fourth International Conference on Internet and Web Applications and Services IEEE , 322-327.

[Downes 05] Downes, S.: "E-learning 2.0", ELearn Magazine: education and technology in perspective, Vol. 2005, Num.10, http://elearnmag.org/subpage.cfm.

[Farmer and Dolphin 05] Farmer, J., Dolphin, I.: "Sakai: e-Learning and More"; Proc. In EUNIS Leadership and Strategy in a Cyber-Infraestructure World, Manchester, UK, (2005).

[First PHP-OKI 07] First PHP O.K.I. Summit, September 2007. On-line access: http://sourceforge.net/apps/mediawiki/harmoni/index.php?title=First_PHP_O.K.I._Summit.

[Franc 08] Franc, A.: "Outside-in: Application interoperability using an OSID-based framework"; Middlebury College LIS Articles, Presentations, and Posters (2008).

[Freitas 06] Freitas, S.D.: "Learning in Immersive worlds: A review of game-based learning"; Joint Information Systems Committee (JISC) (2006).

[Garreta and Santanach 10] Garreta, M., Santanach, F.: "An Open Environment for e-learning: Combining user-centered design, standards and web 2.0 tools"; In 2010 Third International 
Conference of Education, Research and Innovation. ISBN: 978-84-614-2439-9, Madrid Spain, pp.4981-4987.

[IMS-GLC 09a] IMS-GLC.: "Simple Learning Tools Interoperability", (2009). On-line access: http://simplelti.appspot.com/

[IMS-GLC 09b] IMS-GLC: "Basic Learning Tool Interoperability”, (2009). On-line access: http://www.imsglobal.org/lti/

[Lowendahl 11] Lowendahl, J.M.: "Approaching the Learning Stack: The Third-Generation LMS at Universitat Oberta de Catalunya"; Case Study, Gartner Industry Research publication ID Number: G00210893, (2011).

[MacKenzie et al. 06] Mackenzie, C.M., Laskey, K., Mccabe, F., Brown, P.F, Metz, R.: "Reference Model for Service Oriented Architecture 1.0"; OASIS Standard (2006). On-line access: http://www.oasis-open.org/committees/download.php/19679/soa-rm-cs.pdf

[Megias et al. 09] Megias, D., Tebbens, W., Bijlsma, L., Santanach, F.: "Free Technology Academy: a European initiative for distance education about Free Software and Open Standards"; Proceedings of the 14th annual ACM SIGCSE conference on Innovation and technology in computer science education, ITiCSE '09 (2009). On-line access: http://dl.acm.org/citation.cfm?id=1562904

[Obexer and Bakharia 05] Obexer, R., Bakharia, A.: "OLT System Review” (2005).

[OKI 02] OKI: "Open Knowledge Initiative: What is the Open Knowledge Initiative? White Paper". (2002); The Open Knowledge Initiative.

[Olivier and Liber 01] Olivier, B., Liber, O.: "Lifelong Learning: The Need for Portable Personal Learning Environments and Supporting Interoperability Standards"; in The JISC Centre for Educational Technology Interoperability Standards, Bolton Institute, Bristol, 2001.

[O'Reilly 07] O'Reilly, T.: "What is Web 2.0: Design patterns and business models for the next generation of software"; Communications and Strategies (2007), 65, 17.

[Santanach et al. 07a] Santanach, F., Dalmau, J.C., Casado, P., Alier, M.: "Proyecto CAMPUS. Una plataforma de integración"; IV Simposio Pluridisciplinar sobre Diseño, Evaluación y Desarrollo de Contenidos Educativos Reutilizables. SPDECE 07.

[Santanach et al. 07b] Santanach, F., Gener, M., Almirall, M.: "The Campus Project: e-learning tools and platforms integration"; The Campus Project: e-learning tools and platforms integration.

[Severance et al. 10] Severance, C., Hanss, T., Hardin, J.: "IMS Learning Tools Interoperability: Enabling a Mash-up Approach to Teaching and Learning Tools"; Technology, Instruction, Cognition and Learning (2010) 7, 245-262.

[Sclater 08] Sclater, N.: "Web 2.0, personal learning environments, and the future of learning management systems"; Research Bulletin 13, 2008-2009.

[Squire 05] Squire, K.: "Game-based Learning: Present and Future State of the Field"; MASIE Center (2005).

[Tebbens et al. 10] Tebbens, W., Megías, D., Jacovkis, D., Bijlsma, L.: "Free Technology Academy: a Joint Venture of Free Software and OER"; Proceedings OpenED 2010 Conference, Barcelona, Spain (2010). On-line access: http://hdl.handle.net/10609/4850

[Vavoula and Sharples 02] Vavoula, G.N., Sharples, M.: "KLeOS: A personal, mobile, knowledge and learning organisation system"; Proceedings of the IEEE International 
Workshop on Mobile and Wireless Technologies in Education (WMTE2002), Vaxjo, Sweden, 152-156.

[Wesh 09] Wesh, M.: "From knowledgable to knowledge-able: learning in new media environments". On-line access:

http://www.academiccommons.org/commons/essay/knowledgable-knowledge-able, 2009. 